\title{
Overweight and obesity in the Eastern Mediterranean Region: can we control it?
}

\author{
A.O. Musaiger ${ }^{1}$
}

SUMMARY Obesity has become an epidemic problem worldwide, and in the Eastern Mediterranean Region the status of overweight has reached an alarming level. A prevalence of $3 \%-9 \%$ overweight and obesity has been recorded among preschool children, while that among schoolchildren was $12 \%-25 \%$. A marked increase in obesity generally has been noted among adolescents, ranging from $15 \%$ to $45 \%$. In adulthood, women showed a higher prevalence of obesity $(35 \%-75 \%)$ than men $(30 \%-60 \%)$. Several factors, such as change in dietary habits, socioeconomic factors, inactivity and multiparity (among women) determine obesity in this Region. There is an urgent need for national programmes to prevent and control obesity in the countries of the Region.

\section{Introduction}

The prevalence of obesity is increasing worldwide although the proportion varies from country to country and between geographical areas within a country. Changes in lifestyle, dietary habits, physical activity and the social and cultural environment are associated with the occurrence of obesity [1]. It is well documented that morbidity and mortality rates increase with increase in body weight. Many chronic, noncommunicable diseases are positively associated with obesity, type 2 diabetes mellitus in particular, hypertension, some forms of cancer and cardiovascular disease. These are the main causes of morbidity and mortality in most countries of the Eastern Mediterranean Region. Therefore, prevention and control of obesity can play an important role in reducing the risk for chronic diseases.
This paper highlights the current situation of obesity in the Region and the factors contributing to its prevalence.

\section{Current status of obesity}

Several studies have been carried out to determine prevalence of overweight and obesity in this Region. Most of these studies used the body mass index (BMI) as an indicator for obesity (BMI $<25.0-29.9 \mathrm{~kg} / \mathrm{m}^{2}$ $=$ overweight; $\mathrm{BMI} \geq 30.0 \mathrm{~kg} / \mathrm{m}^{2}=$ obese). Only very few of them used skin fold measurements. It was concluded that overweight and obesity are a cause of concern not only among adults, but also among children and adolescents [2].

De Onis and Blössner reviewed the prevalence of overweight among preschool children ( $0-5$ years) in 94 countries [3]. The global prevalence of overweight was

${ }^{1}$ Director, Directorate of Nutritional Studies, Bahrain Centre for Studies and Research, Manama, Bahrain.

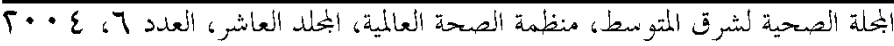


3.3\%. Eastern Mediterranean countries, however, showed the highest prevalence of overweight, ranging from $3.1 \%$ to $9.0 \%$. The prevalence of overweight continues to increase in the Region during the school age and adolescent stages. The World Health Organization reported that BMI begins to increase rapidly after a period of reduced adiposity during the preschool years [1]. During adolescence, children displayed an increase in body fat, often associated with irregular meals, changing food habits and inactivity. In Kuwait, for example, AlMousa and Parkash found that $4.7 \%$ of male and $6.7 \%$ of female preschool children ( $0-5$ years) were obese [4]. The proportion increased to $8.1 \%$ and $8.8 \%$ for schoolchildren aged 6-9 years, and to $36.8 \%$ and $35.9 \%$ for those aged $10-13$ years.

Excluding poorer countries in the Region (Afghanistan, Djibouti, Mauritania, Somalia, Sudan and Yemen) the prevalence of overweight and obesity among schoolchildren aged $6-10$ years was $12 \%-25 \%$, while among adolescents (11-18 years) it was $15 \%-45 \%$, using BMI as a criterion for obesity [5]. Among adults ( $\geq 19$ years) the prevalence of obesity varied widely from country to country. The proportion of overweight and obesity (BMI $\geq 25 \mathrm{~kg} / \mathrm{m}^{2}$ ) among men ranged from $30 \%$ to $60 \%$, while among women it ranged from $35 \%$ to $75 \%$. Some of the studies reviewed were not done on a national basis; they do, however, provide useful data on the trend for obesity [6]. In a review of 39 surveys from 28 developing countries to determine obesity among women, Martorell et al. reported that women in Egypt and Turkey have the highest proportion of overweight (31.7\% for both), as well as the highest proportion of obesity (20.1\% for Egypt and $18.6 \%$ for Turkey) [7].

\section{Factors associated with obesity in the Eastern Mediterranean Region}

During the past decade, there has been increasing emphasis, especially in Saudi Arabia, Bahrain, Egypt, Kuwait, Lebanon and Tunisia, on determining the factors associated with obesity $[2,8,9]$. Nevertheless, indepth studies on this aspect are few, which means there is a grave need for establishing a well-designed, community-based study in the Region.

\section{Change in dietary habits}

Food consumption patterns and dietary habits in this Region have changed markedly during the past 4 decades. There has been an increase in per capita energy and fat intake in all countries. Data from the food balance sheet showed an increase in calories consumed during 1971-1997 in the countries of the Region, and a high percentage of these calories came from animal foods [10]. Over the same period, daily per capita fat intake showed notable increases, ranging from $13.6 \%$ in Sudan to $143 \%$ in Saudi Arabia [11]. It is probable that the high consumption of foods rich in fats and calories and the sedentary lifestyle among most communities in this Region played an important role in the rise of obesity. This is particularly true with the great shift from traditional foods to more westernized foods, which are characterized by high fat, high cholestrol, high sodium and low fibre.

\section{Sociodemographic factors}

Unlike in Europe and North America, obesity in the Eastern Mediterranean Region is more prevalent in women, urban areas and those of higher socioeconomic status. In Jordan, for example the prevalence of obe- 
sity was $56 \%$ in urban areas compared with $44 \%$ in rural areas. Similar trends were found in Egypt, the Islamic Republic of Iran, Morocco, Oman, Tunisia and Turkey. Lebanon was an exception as obesity was more prevalent among rural than urban women. Interestingly, obesity was more prevalent among unemployed than employed women. In Kuwait, the rate of obesity in unemployed women was $47 \%$ compared to $34 \%$ in employed women. In Saudi Arabia, the values were $79 \%$ and $53 \%$, and in Tunisia $24 \%$ and $15 \%$ respectively [6].

In general, obesity in this Region was found to be more prevalent in people who were young (30-50 years), better educated, currently married, female or unemployed, and in those who watched television more than 2 hours per day, consumed fresh fruit less than 3 times a week and owned cars $[6,8]$.

\section{Inactivity and patterns of physical activity}

Changes in lifestyle and socioeconomic status in this Region have had a significant effect on physical activity. With the availability of cars, the increase in electrical home appliances and more involvement in office work, life has become more sedentary, and the pattern of practising exercise has diminished steeply in most countries. In Egypt, it was found that practising exercise is the activity least done during leisure time in a typical day. Only $2 \%$ of adults (20-70 years) were reported as practising exercise in a typical day, $8.5 \%$ practising during the weekend and $2.5 \%$ during their annual leave [12].

In Saudi Arabia, about $53.5 \%$ of Saudi men aged 19 years and older were totally physically inactive, and another $27.5 \%$ were irregularly active. Only $19 \%$ were active on a regular basis. Physical activity was lower among those who were married, working in the private sector, working 2 shifts, less educated or who had only 1 day off during the week. Time constraints seemed to be the major contributing factor to inactivity, while maintaining health and losing weight were the most important reasons for engaging in physical activity among Saudi men [13].

Pregnancy and multiparity have been widely reported as factors contributing to obesity among women. The fertility rate of the women in this Region is very high and the spacing between pregnancies is short, resulting in accumulation of fat in the body. Several studies have been carried out which indicate that obesity is high among women with multiple pregnancies and high parity. In Saudi Arabia, Al-Shammari et al. [14] reported that the mean BMI increased significantly with parity in Saudi women. It was 25.1 in nulliparous women, increasing to $27.1,29.8$ and 31.7 in women with parity $1-2,3-4$ and $>4$ respectively.

\section{Other factors}

There are many other factors, such as home environment, body image, school environment, beliefs and attitudes, lack of health awareness and cultural conditions, which may be linked with obesity but have not been investigated as much.

The decline in exclusive breastfeeding and high dependence on bottle-feeding is another important factor. The World Health Organization reported that promotion of breastfeeding may contribute to the prevention of childhood obesity [15]. Studies in the Region suggest a remarkable decline in exclusive breastfeeding and an increase in the practice of mixed feeding and bottlefeeding.

Television advertising, long periods watching television and using the internet, high intake of fast foods, and increase in

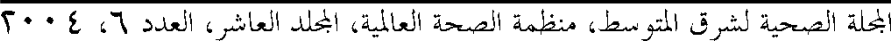


food intake outside the home have also been reported to be associated with obesity among children and adolescents in some countries in the Region [6].

\section{Can we prevent and control obesity?}

Obesity has become one of the major health problems in the Region, and is associated with several chronic diseases. There is no strategy to prevent and control obesity in the health plans of most (if not all) the countries of the Region. Additionally, there is a great lack of quantitative and qualitative research and studies on obesity. This creates the need for affective action, either to study factors contributing to the occurrence of obesity or to establish programmes to control it. In order to achieve this, the following recommendations should be considered.

- Policy-makers should be aware of the importance and seriousness of the problem of obesity and its cost to the health care system budget.

- There is a need to include sound and reliable information on management of obesity in school and university curricula.

- There is a need for a national programme in each country to prevent and control obesity. Such a programme should be part of a national plan to prevent diet-related chronic disease. An obesity control programme should incorporate: dietary management of obesity; promotion of physical activity; health education campaigns; training courses for health workers; the drawing up of regulations and legislation to control advertising of prescription drugs and equipment that claim to reduce obesity; and consideration of the possibility of providing facilities for practising physical activity and exercise in the community.

\section{References}

1. Obesity: preventing and managing the global epidemic. Geneva, World Health Organization, 1998 (WHO Technical Report Series, No. 894).

2. Musaiger $A O$, ed. Proceedings of the first conference on obesity and physical activity in the Arab countries, Bahrain, 2426 September 2002. Arab journal of food and nutrition, 2003 (special issue).

3. de Onis M, Blössner M. Prevalence and trends of overweight among preschool children in developing countries. American journal of clinical nutrition, 2000, 72(4):1032-9.

4. Al-Mousa Z, Parkash P. Prevalence of overweight and obesity among Kuwaiti children and adolescents. Bahrain medical bulletin, 2000, 22(3):123-7.
5. Must A, Dallal GE, Dietz WH. Reference data for obesity: 85th and 95th percentiles of body mass index (wt/ht ${ }^{2}$ ) and triceps skinfold thickness. American journal of clinical nutrition, 1991, 53(4): 839-46.

6. Musaiger AO. Socio-cultural factors affecting obesity in the Arab countries. Bahrain, Bahrain Centre for Studies and Research, 2003 (Technical report).

7. Martorell R et al. Obesity in women from developing countries. European journal of clinical nutrition, 2000, 54(3):247-52.

8. Musaiger AO, Mistery N. Obesity in the Arab Gulf countries: an annotated bibliography. Bahrain, Bahrain Centre for Studies and Research, 2000. 
9. Sibai AM et al. Prevalence and covariates of obesity in Lebanon: findings from the first epidemiological study. Obesity research, 2003, 11(11):135361.

10. Food balance sheet. Rome, Food and Agriculture Organization, 2000.

11. Musaiger AO. Diet and prevention of coronary heart disease in the Arab Middle East countries. Medical principles and practice, 2002, 11(suppl. 2):9-16.

12. Yasin A. Time expenditure in Egyptian community. Cairo, National Centre for Social and Crime Studies, 1998 (in Arabic).
13. Al-Rafaee SA, Al-Hazzaa HM. Physical activity profile of adult males in Riyadh City. Saudi medical journal, 2001, 22(9):78-9.

14. Al-Shammari SA et al. High prevalence of clinical obesity among Saudi females: a prospective, cross-sectional study in the Riyadh region. Journal of tropical medicine and hygiene, 1994, 97(3): 183-8.

15. Diet, nutrition and the prevention of chronic diseases. Geneva, World Health Organization, 2003 (WHO Technical Report Series, No. 916).

FAO/WHO Regional technical consultation on national food-based dietary guidelines

The World Health Organization (WHO) and Food and Agriculture Organization (FAO) are organizing the regional technical consultation on national food-based dietary guidelines, in Cairo, Egypt, from 6 to 9 December 2004. The objectives of the consultation are to: review the status of food-based dietary guidelines in Member States; assist Member States in formulating national food-based dietary guidelines; and develop the framework of a regional food-based dietary guideline. Experts from Bahrain, Egypt, Greece, India, Kuwait, Jordan, Pakistan, Qatar, Saudi Arabia, and the USA, as well as WHO concerned staff, will be attending this consultation.

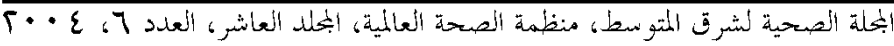

